\title{
Review paper
}

\section{Underrated enemy - from nonalcoholic fatty liver disease to cancers of the gastrointestinal tract}

\author{
Aleksandra Derra*, Martyna Bator*, Tomasz Menżyk, Michał Kukla \\ Department of Gastroenterology and Hepatology, Medical University of Silesia in Katowice, Poland \\ *These two authors contributed equally to this work
}

\begin{abstract}
Nonalcoholic fatty liver disease (NAFLD) is intrahepatic ectopic lipid deposition which is present despite a lack of other causes of secondary hepatic fat accumulation. It is the most common chronic liver disorder in the welldeveloped countries. NAFLD is a multidisciplinary disease that affects various systems and organs and is inextricably linked to simple obesity, metabolic syndrome, insulin resistance and overt diabetes mellitus type 2. The positive energy balance related to obesity leads to a variety of systemic changes including modified levels of insulin, insulin- like growth factor-1, adipokines, hepatokines and cytokines. It is strongly linked to carcinogenesis and new evidence proves that NAFLD is associated with higher risk of all-cause mortality and cancer-specific mortality among cancer survivors. This article focuses on the association between NAFLD and extrahepatic gastrointestinal tract cancers, aiming to shed light on the pathomechanism of changes leading to the development of tumors.
\end{abstract}

Key words: obesity, insulin resistance, carcinogenesis, adipokines, NAFLD.

\section{Address for correspondence}

Aleksandra Derra, Department of Gastroenterology and Hepatology, Medical University of Silesia, 14 Medyków St., 40-752 Katowice, Poland, e-mail: oladerra@gmail.com

\section{Introduction}

Nonalcoholic fatty liver disease (NAFLD) is an increasingly recognized disorder characterized by intrahepatic ectopic lipid deposition which is present despite a lack of other causes of secondary hepatic fat accumulation (e.g., heavy alcohol consumption, hepatitis B or C, autoimmune hepatitis, toxins, etc.) [1]. It is the most common chronic liver disorder in the well-developed countries. The estimated prevalence of NAFLD ranges from $10 \%$ to $25 \%$. The prevalence depends on several factors including age, gender, ethnicity, kind of diet and life style (physical activity) [2-4]. The term NAFLD encompasses various histological diagnoses from pure (simple) steatosis - nonalcoholic fatty liver (NAFL), through nonalcoholic steatohepatitis (NASH), cirrhosis and hepatocellular carcinoma (HCC). The definition of NAFL is the presence of hepatic steatosis with no evidence of hepatocellular injury revealed by ballooned hepatocytes. NASH is defined as the presence of histological hallmarks including hepatic steatosis, intralobular inflammation and hepatocyte ballooning regardless of the presence of fibrosis [1]. Non-alcoholic fatty liver disease is more prevalent in the group of patients with metabolic syndrome and insulin resistance (IR). There is strong evidence of associations between NAFLD and type 2 diabetes mellitus (T2DM), abdominal obesity, dyslipidemia, and arterial hypertension $[3,5,6]$. Obesity is a risk factor for both cancer development with poor outcomes in different tumor types and NAFLD. The positive energy balance related to obesity leads to a variety of systemic changes including modified levels of insulin, insulin-like growth factor-1 (IGF-1), leptin, adiponectin and other adipokines, hepatokines, steroid hormones and cytokines. Furthermore, an overabundance of circulating free fatty acids (FFAs) potentiates hepatic lipid storage, increases oxidative stress and accelerates IR $[7,8]$. Two essential types of NAFLD have been postulated, genetic and metabolic, with the primary role of IR and 
abdominal obesity in the latter [9]. The "multi parallel hits hypothesis" postulates multiple metabolic and environmental factors impacting together on genetically predisposed subjects [10]. The presence of NAFLD is closely associated with extrahepatic serious abnormalities including cardiovascular system with atherosclerosis/cardiovascular disease (CVD) and hypertension, endocrinopathies, T2DM, chronic kidney disease and osteoporosis [11]. The risk of developing these cardiometabolic diseases parallels the underlying severity of NAFLD. Accumulating evidence suggests that the presence and severity of NAFLD are associated with an increased risk of incident T2DM and hypertension [12]. It is strongly linked with carcinogenesis and not only leads to HCC, but also is proven to be an independent risk factor of colorectal polyps and cancer development. Although the basic liver pathology refers to hepatic structure and function to cause morbidity and mortality from cirrhosis, liver failure and HCC, the majority of deaths among NAFLD patients can be assigned to cardiovascular disease [13]. New evidence proves that NAFLD is associated with higher risk of all-cause mortality and cancer-specific mortal- ity among cancer survivors [14]. This article focuses on the association between NAFLD and extrahepatic gastrointestinal tract cancers in order to shed light on the growing problem of complications among patients with NAFLD.

\section{Pathogenesis}

\section{Insulin resistance}

Insulin plays a great role as a metabolic regulator, but it also acts as a growth factor with proliferative and mitogenic activities (Fig. 1) [15, 16]. Insulin resistance is often considered as the primary cellular defect in the development of T2DM. The definition of IR assumes that it is a state which requires higher-than-normal insulin concentrations to obtain suitable biological effects $[17,18]$. The combination of IR and consequent hyperinsulinemia leads to hyperglycemia and the development of conditions associated with T2DM. However, the majority of obese and insulin-resistant subjects initially do not develop hyperglycemia because of the compensatory capacity of the islets of Langerhans and

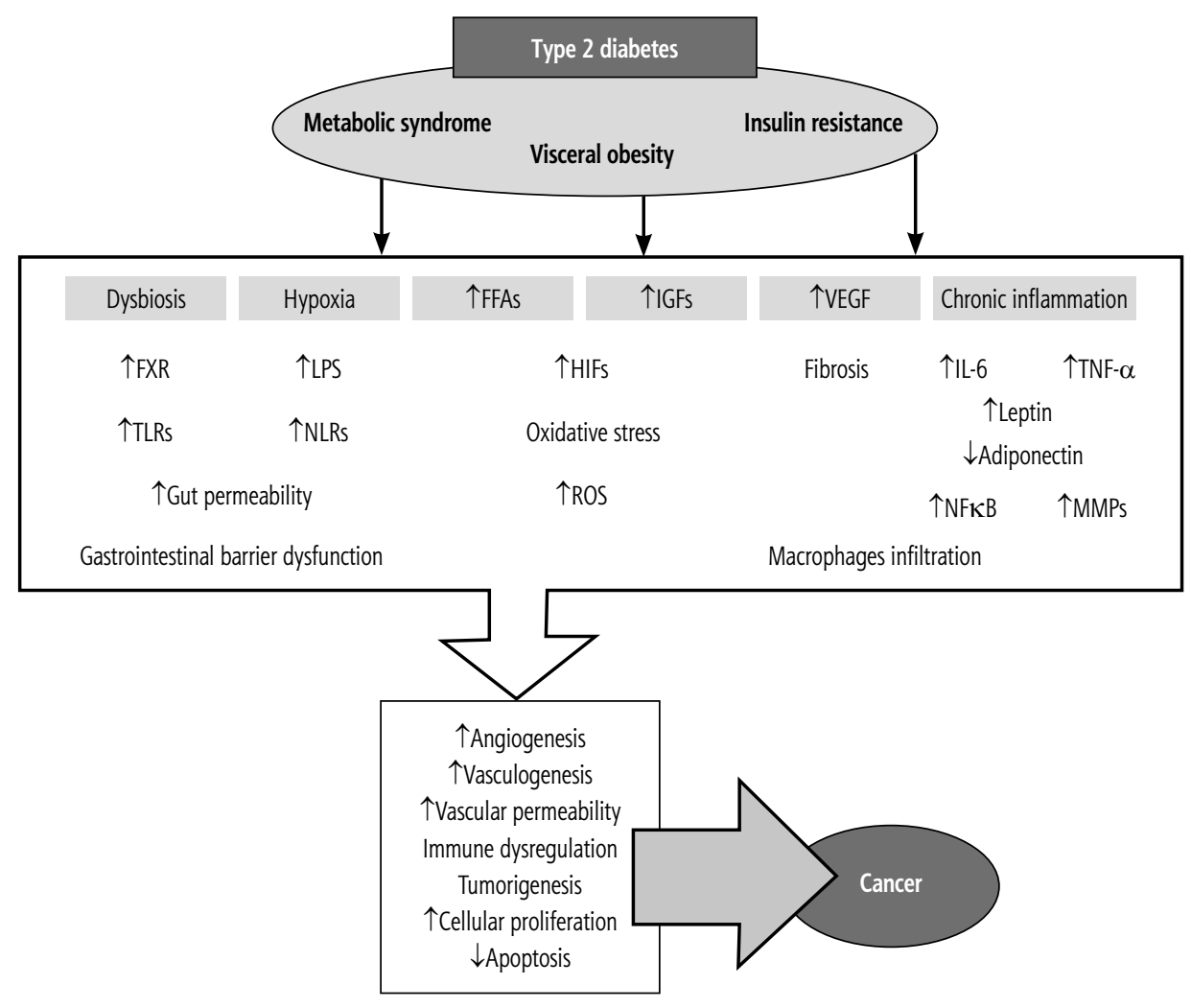

FFAs - free fatty acids, IGFs - insulin-like growth factors, VEGS - vascular endothelial growth factor, FXR - farnesoid X receptor, TLRs - Toll-like receptors, LPS - lipopolysaccharide, NLRS - NOD-like receptors, HIFs - hypoxia-inducible factors, ROS - reactive oxygen species, IL-6 - interleukin-6, TNF- $\alpha$ - tumour necrosis factor a, NFK B - nuclear factor kappa B, MMPs - matrix metalloproteinases

Fig. 1. Association between non-alcoholic fatty liver diseases and the mechanism of carcinogenesis 
an elevated hormone output [19-21]. The positive energy balance related to obesity leads to an excess of circulating FFAs, increased oxidative stress and accelerated IR [7]. Short-term exposure to FFAs results in increased insulin secretion following a meal and enables storage of excess energy as fat, while long-term exposure to FFAs involves impaired glucose metabolism, reduced insulin biosynthesis and beta cell loss [22, 23]. There is also evidence of the important role of chronic hepatitis $\mathrm{C}$ as a special type of metabolic disease, associated with hepatic steatosis due to lipid metabolism abnormalities, but also IR and T2DM as a result of impaired glucose metabolism [24].

Activation of the insulin receptor (Ir) under hyperinsulinemic condition results in up-regulation of the mitogenic pathway [25]. The insulin receptor is a transmembrane receptor which belongs to the large class of tyrosine kinase receptors. Ligands of this receptor include insulin, insulin growth factor (IGF)-1 and IGF-2 [15]. Alternative splicing of the Ir gene causes presence of two isoforms - IrA and IrB. These receptors are tetrameric proteins consisting of two $\alpha$ - and two $\beta$-subunits. Indeed IrA differs from IrB by the exclusion of exon 11, and the additional 12 amino acids remain present at the C-terminus of the IR $\alpha$-subunit [26, 27]. The isoforms of IR differ in affinity for IGFs, internalization and recycling rate, which is higher and greater in favor of IrA $[28,29]$. Consequently, IrB exhibits an association with metabolic and differentiating signals and is highly specific for insulin, while IrA plays an essential role in mitogenic and antiapoptotic signals induced mainly by IGF-2 (with lesser affinity for IGF-1) $[28,30]$.

As a growth factor to stimulate mitogenesis insulin activates the Ras-Raf-Map kinase signaling pathway [31]. Insulin binds to its receptor on the cell membrane, leading to phosphorylation/activation of insulin receptor substrates (IRSs). The Shc protein binds phosphorylated Ir and IRS-1, whereupon they serve as effective adapters for the GRB2-SOS complex. The complex activates Ras and the mitogen activated protein kinase (MAPK) cascade [32, 33]. The Ras-MAPK pathway leads to activation of genes involved in the mitogenic response to insulin and the IGFs, promoting inflammation and atherogenesis $[34,35]$.

Insulin growth factors have primary structural homology to proinsulin. Most of them are produced by hepatocytes in response to growth hormone stimulation $[36,37]$. In addition to IGFs, the IGF axis includes two receptors - IGF1R and IGF2R - and a family of high-affinity IGF-binding proteins (IGFBPs). IGFs are stimulators of mitogenesis, survival and cellular transformation. Insulin, pro-insulin and IGFs with different affinities and potencies are capable of binding and acti- vating both Ir and IGF-1R. IGF2R has a higher affinity for IGF2, and its main function is modulation of the bioavailability of extracellular IGF-2 [38-40].

All IGFBPs serve as growth-inhibitory factors by competitively binding IGFs and preventing their binding to IGF1R, which stimulates cell proliferation. IGFBPs modulate the amount of bioavailable free IGFs and reduce their transfer from the bloodstream to tissue, inhibiting their action [39].

Growing evidence indicates that NAFLD aggravates IR and is an independent risk factor for developing and worsening of existing T2DM. Many studies also demonstrate that fatty liver with IR plays an important role in development of chronic complications, such as CVD, chronic kidney disease and extra-hepatic cancers [11, 41-43]. Due to IR progression among patients, hyperinsulinemia leads to higher production of IGF-1, resulting in activation of cellular growth and proliferation and down-regulation of apoptosis [36, 38, 44]. Up-regulated and uncontrolled cellular growth and proliferation within the organs may contribute to carcinogenesis. Higher IGF expression was associated with tumor progression in colorectal and pancreatic caners [45-47]. Increased levels of IGF-1 and its receptor in gastrinomas were related to accelerated tumor growth and aggressiveness, and occurrence of liver metastases [48]. It has been identified that IGF-1 activated various pathways of the epithelial-mesenchymal transition (EMT) in gastric cancer. IGF-1 signaling activated survivin (BIRC5) expression and controlled the expression of EMT biomarkers during the development of gastric cancer [49]. There is also evidence that a higher IGF-1/ IGFBP-3 molar ratio represents increased free IGF-1, which may be a risk factor for pancreatic cancer [50]. IGF-2 expression was significantly increased in primary colon tumors [51].

\section{Angiogenesis}

Insulin also induces production of a variety of other potential regulators of cell proliferation and differentiation, such as cytokines, adipokines and growth factors including leptin, vascular endothelial growth factor (VEGF) and interleukin(IL)-6 [52-54]. Binding to IGF1R, it plays an important role in increased production of VEGF by endothelial cells $[37,55,56]$. VEGF is not only a trigger and regulator of angiogenesis, vasculogenesis and vascular permeability, but VEGF-mediated signaling influences key aspects of tumorigenesis, including the function of cancer stem cells and tumor initiation [56, 57]. The role of VEGF overexpression is proven in gastric cancer, esophageal cancer and colorectal cancer $[55,58-61]$. 
During chronic inflammation, which is an inherent element of excess hypotrophy of adipose tissue and NAFLD, the accumulation of inflammatory cells collectively with fibrosis leads to hypoxia, by aggravating resistance of damaged tissue to blood flow and oxygen $\left(\mathrm{O}_{2}\right)$ supply $[62,63]$. Hypoxia induces angiogenesis as a result of signaling mediated by hypoxia-inducible factors (HIFs) [64]. Three isoforms of HIFa subunits (HIF-1 $\alpha$, HIF-2 $\alpha$, and HIF-3 $\alpha$ ) expression and the downstream activation of the hypoxic stress response play an important role in many cancers. HIF- 1 and HIF2 play complementary roles in the regulation of erythropoiesis, angiogenesis, cell proliferation and apoptosis. Each HIF regulates a unique subset of target genes. HIFa stabilization has a role in genetic alterations such as mutations in the $\mathrm{Wnt} / \beta$-catenin signaling pathway in colon carcinoma and other oncogenic events [65-68].

However, some data show that hypoxia alone could be important in the stimulation of angiogenesis and can also boost inflammation, causing a circle between inflammation and angiogenesis [69]. Interestingly, evidence showed that in morbidly obese patients the activation of angiogenesis was observed very early at the stage of simple steatosis, while in non-obese patients angiogenesis took place later at the level of NASH. In severe obesity, there was also a positive association between the progression of fibrosis and neovascularization activity $[65,70]$.

In a study performed on 72 patients with chronic hepatic disease, infected with hepatitis $\mathrm{C}$ virus genotype $1 \mathrm{~b}\left(\mathrm{BMI}<30 \mathrm{~kg} / \mathrm{m}^{2}\right)$, Kukla et al. demonstrated that higher grades of steatosis are positively associated with a more advanced stage of fibrosis and CD34 expression [71]. CD34 is a sialomucin-like glycoprotein expressed on hematopoietic progenitor cells, normal vascular endothelium and fibroblasts, which has been used as an endothelial antigen to emphasize vascular density as a direct indicator of neoangiogenesis in cancers [72].

\section{Inflammation}

Adipose tissue includes mature adipocytes, stromal preadipocytes, but also immune cells, extracellular matrix and the vascular endothelium [73]. IR, excessive release of FFAs and ectopic fat deposition are promoted by macrophage infiltration [74]. Adipocytes, macrophages and the interaction between them cause lipotoxicity-induced metabolic dysfunction. Activation of inflammatory pathways and adipocyte necrosis induces "signals" (adipokines, hormones) that locally recruit macrophages. This leads to adipocyte-macrophage crosstalk aggravating lipotoxicity and IR [74-77].
Low-grade chronic inflammation and IR create a specific microenvironment, which is suitable for cancer development due to stimulation of the IGF-1 axis by hyperinsulinaemia [78]. The chronic inflammatory state is likely to be associated with increased production of IL- 6 by adipose tissue. Expression of this cytokine positively correlates with IR both in vivo and in vitro $[52,79]$. Proinflammatory cytokines, such as tumor necrosis factor (TNF)- $\alpha$, IL-6, IL- 8 and plasminogen activator inhibitor-1 (PAI-1), play important roles in cellular proliferation, angiogenesis and negative regulation of apoptosis $[80,81]$.

IL-6 acts through several classic protein kinase cascades such as MAPK and phosphatidylinositoltriphosphate kinase (PI-3 kinase), but can also directly activate the signal transducers and activators of transcription (STAT) factors STAT1 and STAT3, due to the capability of acting by Janus kinases (JAK). Activation of these pathways is a serious unwanted consequence in the context of progression to neoplasia [82]. Furthermore, several experimental studies have shown that IL-6 promotes tumorigenesis and angiogenesis, facilitates metastases and increases treatment resistance [82-84]. IL-6 is associated with carcinogenesis in gastric cancer and colorectal cancer [85-87]. Increased expression of IL- 6 was also found in human pancreatic cancer cells [82, 88]. A number of reports also indicate that TNF- $\alpha$ is a very important factor in carcinogenesis. It induces tumor initiation and promotion, mediates proliferation and potentiates invasion of tumor cells. It supports tumor development due to development and persistence of angiogenesis $[89,90]$. Animal models showed higher expression of TNF- $\alpha$ in colorectal cancer [91]. TNF- $\alpha$ influences cancer development by activating the tumorigenic Wnt signaling pathway [92].

\section{Hedhehog}

Hedhehog $(\mathrm{Hh})$ is the best characterized signaling pathway that mediates hepatic fibrosis in NAFLD. This pathway is an accepted master of the wound-healing response, which is a reaction to liver damage $[93,94]$. Deregulation of wound healing promotes the development of progressive fibrosis, which determines liver prognosis [95]. In healthy hepatocytes Hedgehog pathway activation is properly absent, but injured ballooned hepatocytes are the main source of Hh ligands (mostly Sonic hedgehog, Shh; others: Indian hedgehog, Ihh; and Desert hedgehog, Dhh) in NAFLD [94, 96]. In human NAFLD the magnitude of activation of the Hh pathway is related to the severity of liver disease and correlates with the severity of fibrosis $[96,97]$. The number of Shh 
expressing ballooned hepatocytes strongly correlates with fibrosis severity, as well as with the severity of the ductular reaction, which is closely related to fibrogenesis and carcinogenesis [96, 98]. Hh signaling is associated with inflammatory and chronic degenerative diseases. Overactivation of this signaling may lead to many tumors such as pancreatic cancer [99].

\section{Gut microbiota}

Obesity, T2DM and low physical activity induce quantitative and qualitative changes of gut microbiota composition [100]. Dysbiosis of gastrointestinal microorganisms in NAFLD has been confirmed in many studies. There is evidence that children with NAFLD exhibited higher abundance of Gammaproteobacteria, Epsilonproteobacteria and Prevotella spp. than healthy controls [101]. In the case of NASH and obesity the increase of representation of Bacteroidetes and Prevotella was found. In the same study, elevated blood-ethanol concentration was observed among patients with $\mathrm{NASH}$, when compared to healthy subjects and obese patients. The role of alcohol metabolism in oxidative stress and liver inflammation suggests a significant role of the alcohol-producing microbiome in the pathogenesis of NASH [102]. Also the higher Bacteroides concentration is related to NASH development while the increased abundance of Ruminococcus is associated with risk of liver fibrosis [103]. Additionally, the cross talk between the immune system and gut microbiota components plays a key role in maintenance of gastrointestinal epithelial barrier function [104]. Disability of the immune epithelial network leads to dysfunction of tight junctions, increased gut permeability, bacterial translocation and leakage of bacterial components $[105,106]$. Likewise, reports have demonstrated that a decrease in Akkermansia muciniphila, which is observed in the obese, causes a thinner intestinal mucus layer and promotes gut permeability [107].

Gut microbial enzymes facilitate dietary fat digestion and absorption through formation of micelles, which is possible due to the ability of transformation of the primary bile acids into conjugated bile acids. Studies carried out on mice showed that germ-free (GF) mice or antibiotic treated mice had low concentrations of conjugated bile acids; these results underline the central role of the gut microbiota in regulating bile acid composition, conjugation, and diversity [108110]. Bile acids bind the nuclear farnesoid $\mathrm{X}$ receptor (FXR), which is known as a transcription factor controlling their endogenous synthesis and release [111]. Mice with IR and obesity have a low diversity of gut microbiota, associated with a reduction in bile acid composition, higher intestinal expression of FXR and FXR-related genes (FGF15) and decreased hepatic Cyp7a1 [112].

There is strong evidence regarding the role of small intestinal bacterial overgrowth (SIBO) and endotoxemia in NAFLD progression. A critical point is activation of the family of pattern recognition receptors (Toll-like receptors, TLRs) with translocated bacterial endotoxins such as lipopolysaccharide (LPS), bacterial fragments, bacterial DNA and peptidoglycan. Circulating pathogen-associated molecular pattern (PAMPs) and damage-associated molecular patterns (DAMPs) and their interaction with TLRs induce production of reactive oxygen species and activation of the inflammasomes [113-116]. The inflammasome (NLRP3) is a cytosolic multiprotein complex of receptors from the family of NOD-like receptors, with pro-caspase-1 and an adaptor: apoptosis-associated speck-like CARD-domain containing protein (ASC). Activation of the complex causes autocatalytic cleavage and activation of caspase- 1 , which activates IL- $1 \beta$ and IL-18 and neutralizes IL-33. The inflammasomes are present in the liver in parenchymal and non-parenchymal cells $[117,118]$. Increased expression of this multiprotein complex and its components was observed in NASH, which may suggest the key role in NASH development and progression $[119,120]$. Stimulation of TLRs also results in the production of various inflammatory mediators through transcriptional factor nuclear factor kappaB (NF- $\kappa \mathrm{B})$ and/or c-Jun N-terminal kinase (JNK) activation [121]. Changes in the tumoral genetic and immunological microenvironment can lead to malignancy growth in the colon and influence esophageal and pancreatic tumorigenesis [122-124].

\section{Adipokines}

Adipose tissue derived hormones, termed adipokines, play a pivotal role in NAFLD. They have been suggested to significantly influence cell proliferation, apoptosis, carcinogenesis and angiogenesis. They regulate intrahepatic fat accumulation, IR, inflammation and fibrosis [125]. The family of adipokines has been extending in recent years. Some of them exert protective effects, whereas others exert proinflammatory, profibrotic, prosteatotic and procarcinogenic effects [125-129].

In obesity, like NAFLD, leptin levels increase with a simultaneous decrease of adiponectin (Fig. 2) [78, 130]. Leptin is a hormone which is mainly produced by adipose tissue and whose function is to control food intake and energy balance [131]. Circulating leptin levels are higher in patients with NAFLD than in controls, and these are associated with increased severity of 


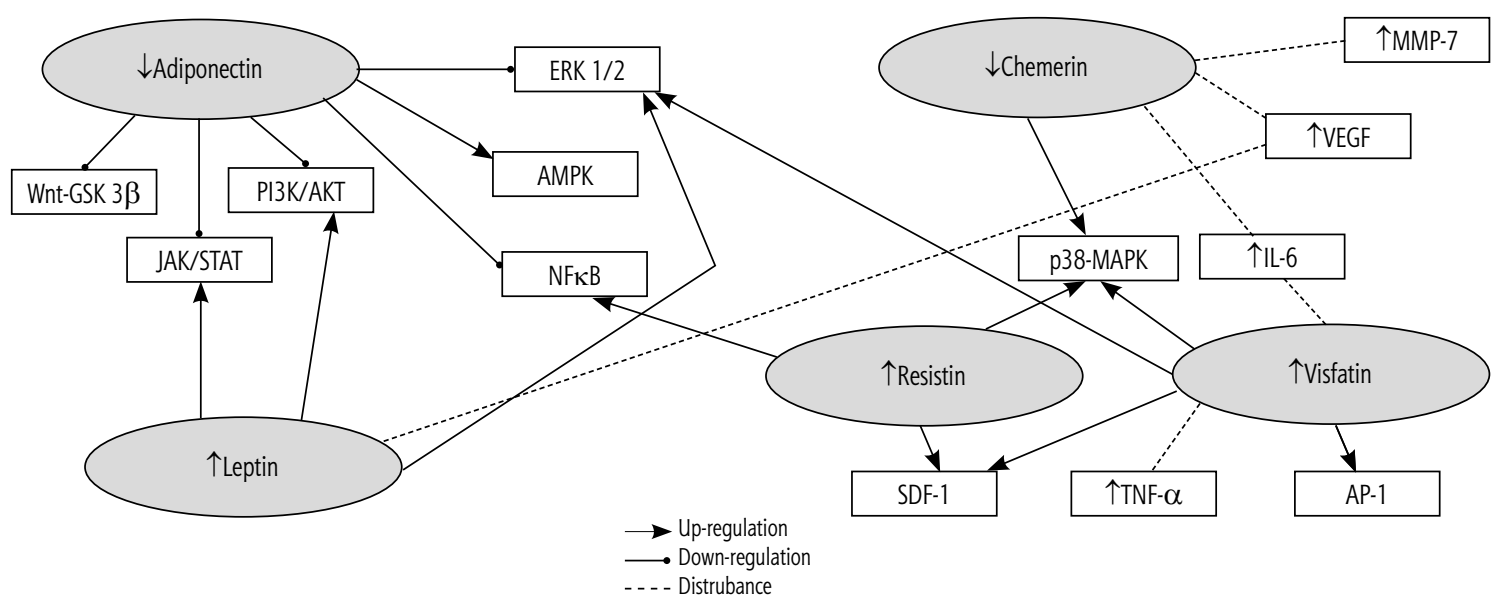

Wnt-GSK $3 \beta$ - glycogen synthase kinase-3 $\beta$ pathway, PI3K/AKT - phosphatidylinositol 3-kinase/protein kinase BPathway, JAK/STAT -janus kinase/signal transducer and activator of transcription pathway, AMPK-AMP - activated protein kinase, ERK 1/2 - extracellular regulated kinase 1 or 2, NF- $k b$ - nuclear factor kappaB, MMP-7 - matrix metalloproteinase 7, VEGF - vascular endothelial growth factor, p38-MAPK-p38 mitogen-activated protein kinase pathway, IL-6 - interleukin-6, SDF-1, stromal cell-derived factor 1, TNF- $\alpha$ - tumor necrosis factor $\alpha, A P-1$ - activator protein-1

Fig. 2. Effect of changes in adipokines concentration in NAFLD on mechanisms involved in the carcinogenesis. In NAFLD serum levels of leptin, resistin, chemerin and visfatin are elevated, which stimulate pathways leading to tumour development. On the contrary, the level of adiponectin, which is responsible for downregulating cancerogenesis-promoting pathways, is decreased

NAFLD $[132,133]$. Leptin is associated with increased carcinogenesis, indirectly through regulation of inflammation and oxidative stress or directly through up-regulation of cell proliferation, inhibition of apoptosis, potentiation of angiogenesis and modulation of the immune response [134]. Its pro-cancerogenic activity takes place through the JAK/STAT (Janus kinase/signal transducer and activator of transcription), PI3K/PTEN/Akt/mTOR (phosphoinositide 3-kinase/ phosphatase and tensin homolog/protein kinase $\mathrm{B} / \mathrm{mam}$ malian target of rapamycin), Raf/MEK/ERK (protooncogene c-RAF/mitogen-activated protein kinase kinase/extracellular signal-regulated kinase) pathways $[130,135]$. There was noted a dependence between elevated levels of leptin and risk of occurrence of esophageal adenocarcinoma in the overweight population [136]. In a study comparing the expression of leptin and adiponectin in esophageal squamous cell carcinoma (122 patients) and normal esophageal mucosa (40 subjects) Duan et al. found that also in esophageal carcinoma there occurs imbalanced expression of adipocytokines and a link of lymph node metastasis and/or tumor stage with expression of leptin and adiponectin, which may have potential significance in carcinogenesis and poor outcomes [137]. Stomach cancer is also linked to leptin levels. Leptin induces proliferation of gastric cancer cells by activating STAT3 and ERK1/2 pathways. It is involved in increasing expression of VEGF and mediating angiogenesis, which is engaged in tumor progression $[138,139]$. Expression of the leptin receptor $(\mathrm{Ob}-\mathrm{R})$ depending on clinical stage was assessed, and it showed a tendency to increase from gastric adenoma (2\%), through early gastric cancer (8\%), to advanced gastric cancer (18\%) [138]. In the same study, an association between leptin expression and incidence of cardia cancer location was demonstrated. Colorectal cancer studies documented a link between increased serum leptin levels and lymph node involvement, microvascular invasion and advanced tumor stage [134, 140,141]. Wang et al. confirmed this correlation in a study including 108 patients (57 males/51 females, mean age 58.9 years) with tumors located in the colon in 78 and the rectum in 30 patients. The distribution by TNM stage at diagnosis was: stage I in 24 patients, stage II in 27 patients, stage III in 45 patients, and stage IV in 12 patients [141]. Leptin could regulate proliferation and apoptosis of colorectal cancer through the PI3K/Akt/mTOR signal pathway [141]. At early stages of colorectal cancer it also acts as a growth factor through activation of the signal transducer and activator of transcription 3 (STAT 3) pathway [142].

Adiponectin is a $30 \mathrm{kDa}$ protein hormone produced and secreted almost exclusively by adipocytes, which demonstrates insulin-sensitizing, vascular-protective and anti-inflammatory properties [140]. In serum this adipokine occurs in three forms: trimers, hexamers and high-molecular weight (HMW) multimers, which is the most biologically active isoform $[143,144]$. Three APN receptors have been discovered - AdipoR1, AdipoR2 and T-cadherin. The first two have been reported to be expressed in several cancer 
cells in vitro and in vivo $[144,145]$. Through these receptors adiponectin affects many pathways showing anti-carcinogenic activity. It activates AMP-activated protein kinase (AMPK), which plays a central role in disturbing cellular growth signaling via mTOR and inhibits adhesion and migration of tumor cells [146, 147]. It also acts as an inhibitory factor of the phosphatidylinositol 3-kinase/protein kinase B (PI3K/AKT) pathway, which is activated in a few types of cancers by promoting cellular growth and proliferation by insulin- and growth factor-induced signaling [147]. Adiponectin down-regulates carcinogenesis-promoting glycogen synthase kinase-3 $\beta$ (Wnt-GSK3 $\beta$ ) pathways, extracellular regulated kinase 1 or 2 (ERK1/2), Janus kinase/signal transducer and activator of transcription (JAK/STAT) pathways and NF-кB [147-149]. Hypoadiponectinemia extends the production pro-inflammatory cytokines including TNF- $\alpha$ and IL-6, acting as a pro-inflammatory factor and tumor cell proliferation and angiogenesis promoter $[78,145]$. In NAFLD reduced levels of adiponectin were found [150-152]. Adiponectin serum levels are dependent on abdominal adiposity distribution, with a decreased amount in obese individuals [152]. Lower levels of adiponectin were found to be associated with cancer development. The relationship was confirmed for colorectal, gastric and esophageal cancers [153-156]. Yildırım et al. [153] studied 62 patients ( 30 males/32 females, aged 64 years, BMI $22.2 \mathrm{~kg} / \mathrm{m}^{2}$ ) with esophageal cancer classified into two types based on the histological characteristics: adenocarcinoma and squamous cell carcinoma of the esophagus. They found that the serum adiponectin level in the cancer group was significantly lower than that in the healthy control group. Moreover, it was gradually decreasing with increase in tumor stage. Additionally, the patients with esophageal adenocarcinoma had lower levels of adiponectin than patients with squamous cell carcinoma. Ishikawa et al. [154] in a study of 75 gastric cancer patients divided into two groups depending on the degree of malignancy of differentiated (32 males/11 females) and un-differentiated (22 males/10 females) gastric cancer found that a reduced adiponectin level was associated with an increased risk for gastric cancer and it had a potential role in tumor progression, especially in undifferentiated type cancers in the upper stomach. A study performed on 165 Chinese male patients of the Han nationality aged $\geq 35$ years and with pathologically diagnosed colorectal cancer (CRC) - intraepithelial carcinoma and submucosally invasive carcinoma as early cancer (patients aged 62.1 years, with BMI 23.5 $\mathrm{kg} / \mathrm{m}^{2}$ ) and pathological stage T2 or higher was defined as advanced cancer (patients aged 61.8 years, with BMI $22.4 \mathrm{~kg} / \mathrm{m}^{2}$ ) - confirmed that a decreased level of adiponectin was a strong risk factor for both early and advanced CRC [155].

Resistin is a $12.5-\mathrm{kDa}$ protein of the "resistin-like molecules" (RELMs) family secreted from adipocytes, but it is also produced by monocytes and macrophages $[11,157]$. Some authors have reported higher circulating resistin levels in NAFLD than in control groups $[158,159]$. An increased level of resistin was found in patients with NASH compared to those with simple steatosis, and it was linked to the severity of liver inflammation and fibrosis in those patients [160]. Resistin was suggested to play a pivotal role in adipocyte maturation through the influence on lipid metabolism. Higher levels of resistin may also be related to development of obesity-mediated IR, T2DM and inflammation $[161,162]$. Resistin stimulates growth, differentiation and migration of endothelial cells, which is substantial in the processes of cancerogenesis and angiogenesis [163]. Although levels of resistin might be elevated in obesity-related cancers, it cannot be labeled as a risk predictor of these tumors' occurrence. Higher resistin levels can be considered as a substantive biomarker of obesity-related cancer risk [164]. In a study performed on 85 patients with histologically confirmed gastroesophageal cancer (male/female 61/24; age 60 years) compared to 60 healthy individuals (male/female 47/13; age 58) serum resistin levels were found to be higher in cancer patients compared to controls. Resistin concentration was associated with cachexia and gastroesophageal cancer metastasis development [165]. Resistin stimulates the expression of stromal cell-derived factor 1 (SDF-1), which works as a growth and survival factor in gastric cancer cells. It acts through TLR4 and activation of NKKB and p38 MAPK pathways [166].

Visfatin is an adipokine with multipotential activities, which is expressed not only in visceral adipose tissue but also by peripheral, bone marrow and hepatic lymphocytes, pneumocytes and hepatocytes [129, 167]. Visfatin exerts both extracellular (cytokine-like) and intracellular (enzymatic) functions, which are responsible for its role in the immune, metabolic and stress responses [125]. Visfatin mediates biosynthesis of nicotinamide adenine dinucleotide (NAD) by conversion of nicotinamide to nicotinamide mononucleotide. NAD biosynthesis is involved in inflammation, cellular differentiation and tumor progression through downstream regulators such as sirtuins and poly (ADP-ribose) polymerase (PARP). The sirtuins are responsible for regulation of both cell survival and TNF- $\alpha$ secretion [168-170]. Visfatin demonstrates mostly pro-inflammatory activity by inducing cyto- 
kines such as TNF- $\alpha$ and IL-6 [171]. Visfatin directly interacts not only with Ir but also with the insulin-like growth factor receptor, and can afterwards promote cancer cell proliferation [172]. Some authors reported higher visfatin levels in NAFLD compared to controls [173]. Elevated levels of visfatin were observed in gastric and colorectal cancers [168, 174, 175]. In gastric cancer visfatin levels can reflect the stage of progression. Moreover, elevated preoperative plasma visfatin levels were a poor prognostic factor of 5-year mortality and overall survival in gastric cancer patients [176]. The results of a case-control study by Nakajima et al. carried out on 115 colorectal cancers patients (69 males and 46 females, aged 63.7 years, BMI $\left.22.9 \mathrm{~kg} / \mathrm{m}^{2}\right)$ with mainly recognized well-differentiated adenocarcinoma showed that visfatin may be a good biomarker of cancer malignancy independently of BMI and stage of progression [177]. Visfatin induces stromal SDF-1 expression in colorectal cancer, which is mediated through $\beta 1$ integrin activation, the ERK and p38 MAPK intracellular signaling cascades, and transcription factors such as NF- $\mathrm{\kappa B}$ and activator protein-1 (AP-1) [178].

Chemerin is an adipokine whose expression has been found in different tissues, including the liver, pancreas, lung and adipose tissue. It has been shown to be associated with BMI, plasma triglycerides, blood pressure and IR [179-181]. Some studies have demonstrated both a pro- and anti-inflammatory chimeric nature of chemerin [182]. Kukla et al. reported that levels of chemerin were higher in NAFLD patients than in healthy individuals. In their study they compared 41 Polish patients (26 males and 15 females) with biopsy-proven NAFLD with up-regulated ALT activity, aged 45.7 years, with BMI $30.4 \mathrm{~kg} / \mathrm{m}^{2}$ [179]. The levels of chemerin are generally higher in obesity and IR conditions and decrease after weight loss [183]. Chemerin exerts an insulin-sensitizing effect on $\beta$ cells and adipocytes [184, 185]. It also has been shown to be involved in the development of inflammation. An elevated serum level of chemerin is positively associated with increased expression of visceral adipose tissue macrophage and proinflammatory cytokines such as TNF- $\alpha[183,186]$. Some data indicated higher chemerin levels to be associated with the occurrence of esophageal, gastric and colorectal cancers [187-190]. A study of 36 gastric cancer patients (19 males and 17 females, aged 47-83 years) by Wang et al. showed elevated levels of chemerin in gastric cancer patients compared to controls. Chemerin levels were related to advanced clinical stages and non-intestinal type of gastric cancer [189]. Jian et al. demonstrated in a group of 196 gastric cancer patients (112 males, 84 females,
BMI $23.0 \mathrm{~kg} / \mathrm{m}^{2}$ ) with mainly histological recognition of adenocarcinoma that preoperative increased levels of chemerin are independently associated with poor prognosis of 5-year mortality, adverse events and short overall survival [188]. Chemerin increases phosphorylation of ERK1/2 and p38 MAPKs and enhances the invasiveness of gastric cancer cells by upregulation of VEGF, matrix metalloproteinase 7 (MMP-7) and IL-6 [189]. These factors are well-recognized negative predictors of gastric cancer outcome [191-193].

\section{Association between NAFLD and gastrointestinal cancer}

\section{Esophageal and gastric cancer}

Esophageal cancer is the sixth leading cause of cancer death worldwide [194]. High BMI, which is the main risk factor of NAFLD development, is also listed among all proven risk factors of esophageal adenocarcinoma [195]. NAFLD is independently associated with increased risk of erosive oesophagitis, which may be complicated by oesophageal ulcers, peptic stricture, Barrett's esophagus and oesophageal adenocarcinoma. Also general and central obesity uncomplicated with NAFLD are included among risk factors of esophageal adenocarcinoma, although they have less significance than when associated with NAFLD [196]. Some data also confirm a relationship between MS and development of Barrett's esophagus, which is considered to be a pre-cancerous condition for esophageal adenocarcinoma [197, 198]. Taking into account the influence of MS and obesity on the occurrence of carcinogenic risk factors, it seems that there should be a link between NAFLD and the development of gastric cancer. However, only one retrospective study has confirmed such a relationship. The study included 1840 Turkish patients who underwent esophagogastroscopy, 14 of whom (9 males $/ 5$ females, aged 56-85 years) were diagnosed with distal gastric cancer. NAFLD was found in $35.7 \%$ of cancer patients. The incidence of NAFLD was higher in gastric cancer patients compared to the average incidence in the Turkish population [199].

\section{Pancreatic cancer}

Pancreatic cancer is one of the most common causes of cancer mortality worldwide and is emerging as a growing health problem due to the distinctly poor prognosis $[200,201]$. Some data have shown an association between pancreatic cancer and obesity. There is evidence that being overweight especially in early adulthood is strongly connected with an increased 
risk of pancreatic cancer independently of T2DM prevalence. The duration of overweight and obesity is also relevant, being considerably longer among patients who developed pancreatic cancer. Likewise, a meta-analysis showed an increase of pancreatic cancer risk together with increasing waist circumference [202-204]. A meta-analysis published in 2011 revealed T2DM as a risk factor of pancreatic cancer regardless of gender. The same study showed that T2DM can be considered as an etiologic factor and an early manifestation of pancreatic cancer [205]. NAFLD should be considered as an independent risk factor of pancreatic cancer, but further studies are needed to clarify and confirm this suggestion.

\section{Colorectal cancer}

The risk of colorectal cancer is higher for inflammatory bowel disease and in the case of a history of colorectal cancer in first-degree relatives, increased BMI, red meat intake, cigarette smoking, low physical activity, and low vegetable and fruit consumption [206]. NAFLD is associated with higher prevalence of colorectal lesions and cancer. Hwang et al. presented evidence for an association between NAFLD and increased prevalence of colorectal adenomatous polyps. The study included 2971 participants who underwent colonoscopy, hepatic ultrasonography scanning and biochemical tests such as serum glucose, triglycerides, total cholesterol, high-density lipoprotein cholesterol (HDL-C) and low-density lipoprotein cholesterol (LDL-C). Adenomatous polyps were diagnosed in 556 (19.1\%) subjects. The prevalence of NAFLD in the group of participants with colorectal lesions was $41.5 \%$ versus $30.2 \%$ in the control group. Multivariate analysis revealed NAFLD to be associated with increased risk of colorectal adenomas (OR 1.28; 95\% CI: 1.03-1.60). Higher risk of NAFLD was significant in patients with many adenomatous polyps [207]. The next retrospective cohort study by Lee et al., which included 5517 women who underwent life insurance company health examinations, confirmed those results. Conducted ultrasonography and exclusion criteria allowed NAFLD to be diagnosed in $15.1 \%$ of studied patients. The incidence of adenomatous polyps in patients with NAFLD vs. without NAFLD was respectively 628.0 vs. $185.2 / 10^{5}$ persons/year (RR 1.94; 95\% CI: 1.11-3.40), while that of colorectal cancer was 233.6 vs. $27.0 / 10^{5}$ persons/year (RR 3.08; 95\% CI: 1.02-9.34) [208].

Stadlmayr et al. performed a cross-sectional study including 1211 participants and obtained similar results. The prevalence of colorectal lesions was 34\% in the NAFLD group and $21.7 \%$ in the control group $(p<0.001)$. Additionally, the study confirmed incidence of colorectal lesions to be dependent on patients' sex. The analysis showed that $40 \%$ of male patients with NAFLD included in the study had colorectal lesions compared to $28.3 \%$ of those without NAFLD ( $p=0.010)$, whereas $25.6 \%$ of female patients with NAFLD had colorectal lesions compared to $17.2 \%$ of those without NAFLD $(p=0.014)$. Patients with NAFLD had a higher number of tubular adenomas and colorectal carcinomas, and it was independent of gender [209]. Moreover, some data showed that patients with NAFLD had more multiple polyps [210], which were more often located in the right and transverse colon [211, 212]. Interestingly, patients with NASH had a higher prevalence of adenomas and advanced neoplasms than those with NAFL [212]. Lin et al. found that patients diagnosed with NAFLD were more often complicated with colorectal cancer, which predominantly was located in the sigmoid colon [213]. The majority of the studies showed comparable results, which are collated in Table 1.

However, Touzin et al. in a retrospective cohort study, which included 233 patients, aged $54.7 \pm 6.0$ years, who underwent screening colonoscopies, did not confirm those results. In the ultrasound $94(40.3 \%)$ participants were diagnosed with NAFLD. Colonic adenomas appeared in $24.4 \%$ of patients with versus $25.1 \%$ of those without NAFLD [214]. A prospective observational study conducted by Basyigit et al. including 127 patients found the prevalence of colorectal carcinoma to be significantly lower in patients with NAFLD (4.6\%) compared to those without NAFLD (24.2\%) $(p=0.001)$. Additionally, the incidence of adenomas was higher in the control group than in NAFLD patients ( $25.8 \%$ vs. $20.0 \%)$, but the difference was not statistically significant [215].

\section{Conclusions}

NAFLD is a growing health problem worldwide and has been described as a "global pandemic". NAFLD is related to increased risk of development of some extrahepatic cancers. Additionally, it is associated with an increased risk of all-cause and cancer-specific mortality among cancer survivors. Therefore, it is important to reveal the pathomechanism of changes leading to the development of tumors and provide novel therapeutic approaches. NAFLD is a multidisciplinary disease that affects various systems and organs and is inextricably linked to simple obesity, metabolic syndrome, IR and overt T2DM.

Many factors influence the development of carcinogenesis in the course of NAFLD:

- IR plays a major role in NAFLD-related carcinogenesis. Stimulation of the IGF-1 factor axis by hyper- 


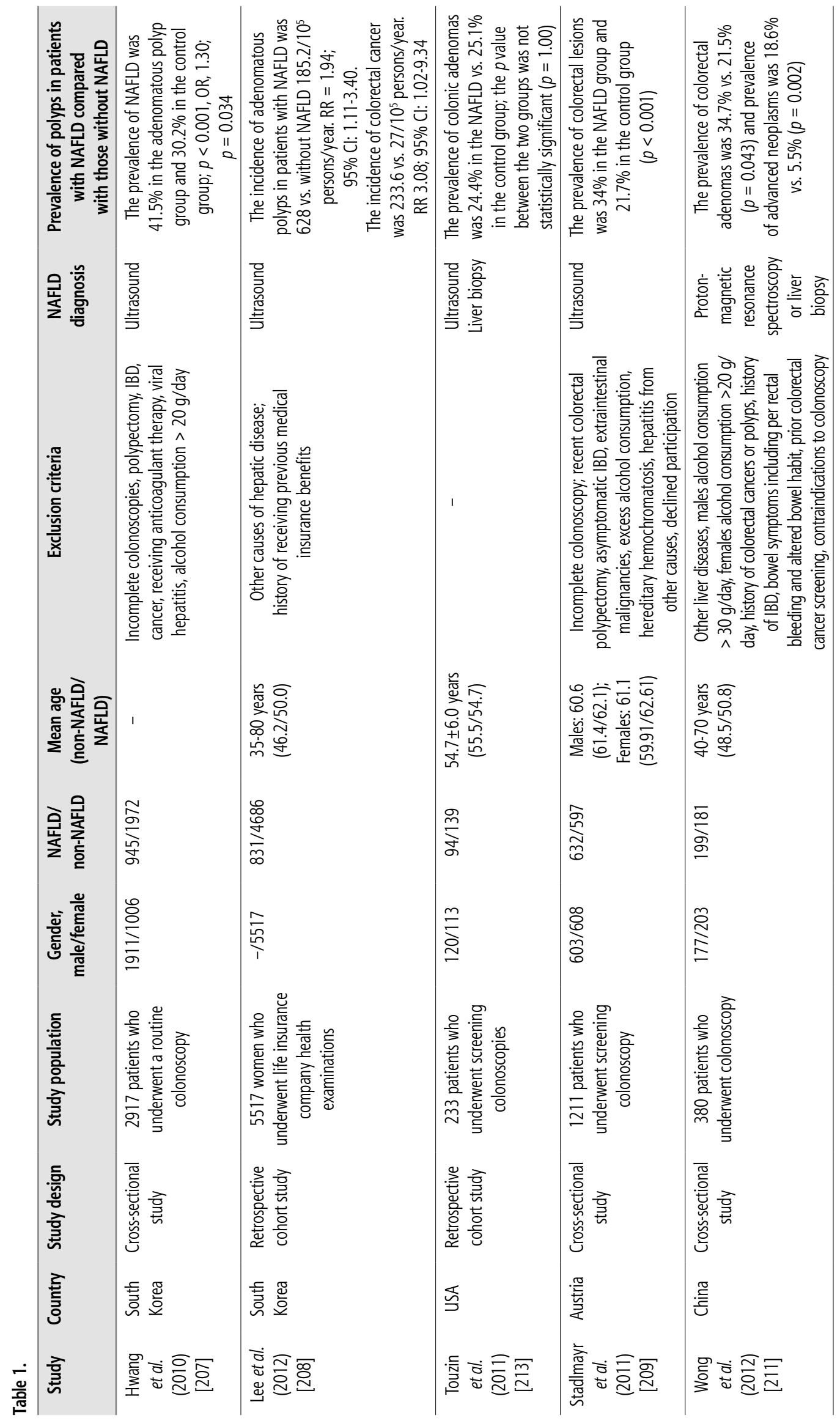




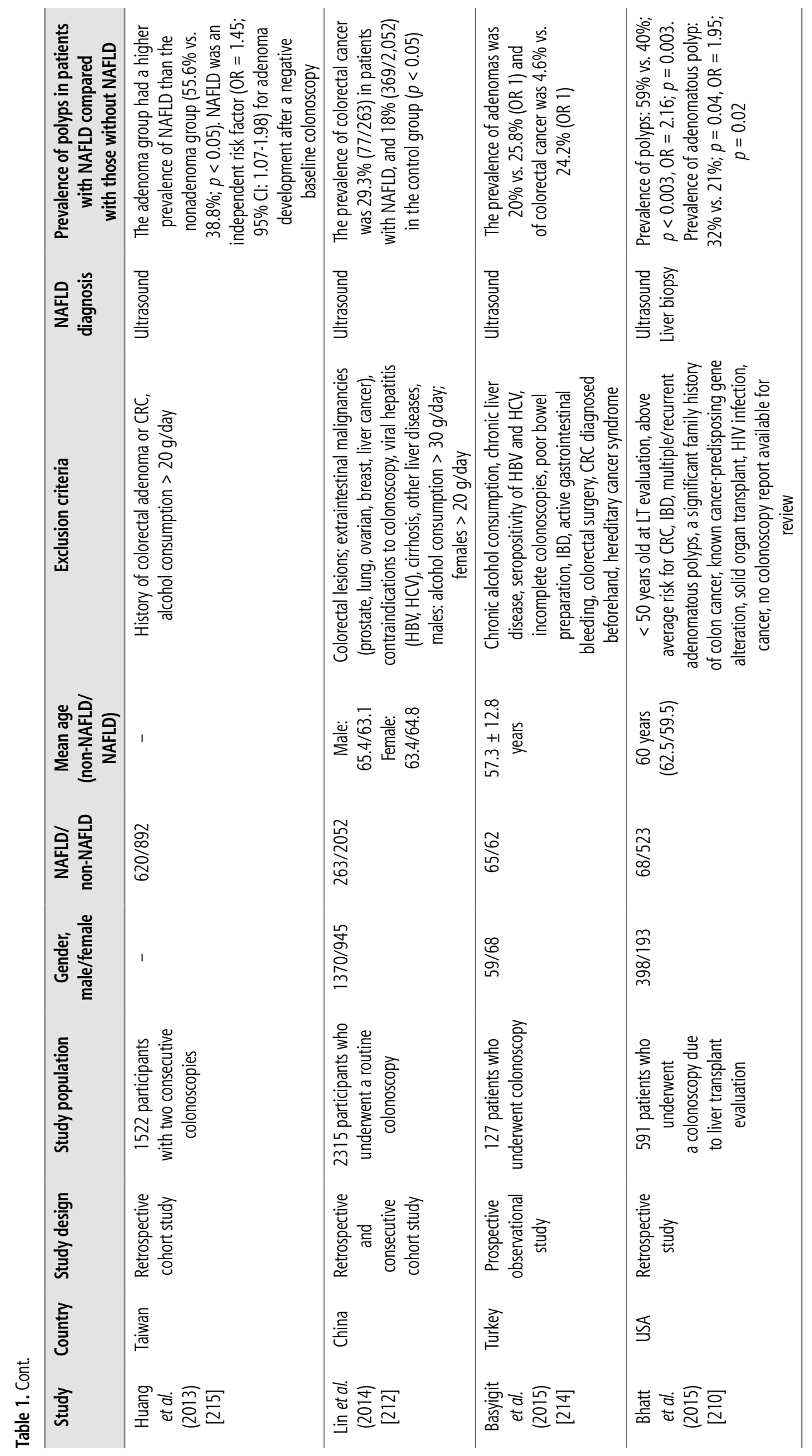


insulinemia leads to enhancement of proliferative and anti-apoptotic pathways.

- Chronic inflammation, aggravated by proinflammatory cytokines and factors, such as TNF- $\alpha$, IL- 6 , IL-8, PAI-1 and NF- $\mathrm{kB}$, which are overexpressed in obesity and NAFLD, accelerates cellular proliferation and angiogenesis, and modulates cellular signaling pathways, which are essential in carcinogenesis.

- Dysbiosis, which is closely associated with obesity, T2DM and NASH, weakens the intestinal barrier. Infiltration of bacterial fragments and products, such as endotoxins, activates TLRs, contributing to exacerbation of the inflammatory process in the liver and adipose tissue, activation of fibrogenesis and up-regulation of oxidative stress and IR.

- Dysregulation of adipose tissue derived hormones adipokines - influences inflammation, fibrosis, angiogenesis, apoptosis and IR, with predominance of the pro-carcinogenic effect.

All these factors are suggested to play a critical role in extrahepatic tumor development. The predominance of pro-carcinogenic risk factors in NAFLD patients results from intricate and multi-faceted mechanisms which still are not fully explained and need further research.

\section{Disclosure}

Authors report no conflict of interest.

\section{References}

1. Chalasani N, Younossi Z, Lavine JE, et al. The diagnosis and management of non-alcoholic fatty liver disease: Practice guideline by the American Association for the Study of Liver Diseases, American College of Gastroenterology, and the American Gastroenterological Association. Am J Gastroenterol 2012; 107: 811-826.

2. Younossi ZM, Koenig AB, Abdelatif D, et al. Global epidemiology of non-alcoholic fatty liver disease - meta-analytic assessment of prevalence, incidence and outcomes. Hepatology 2016; 64: 73-84.

3. Vernon G, Baranova A, Younossi ZM. Systematic review: the epidemiology and natural history of non-alcoholic fatty liver disease and non-alcoholic steatohepatitis in adults. Aliment Pharmacol Ther 2011; 34: 274-285.

4. Abd El-Kader SM, El-Den Ashmawy EMS. Non-alcoholic fatty liver disease: The diagnosis and management. World J Hepatol 2015; 7: 846-858.

5. Lonardo A, Bellentani S, Argo CK, et al. Epidemiological modifiers of non-alcoholic fatty liver disease: Focus on high-risk groups. Dig Liver Dis 2015; 47: 997-1006.

6. Lonardo A, Nascimbeni F, Maurantonio M, et al. Nonalcoholic fatty liver disease: Evolving paradigms. World J Gastroenterol 2017; 23: 6571-6592.

7. Robinson K, Prins J, Venkatesh B. Clinical review: Adiponectin biology and its role in inflammation and critical illness. Critical Care 2011; 15: 221.
8. Temple JL, Cordero P, Li J, et al. A Guide to Non-Alcoholic Fatty Liver Disease in Childhood and Adolescence. Int J Mol Sci 2016; 17: 947.

9. Katira A, Tan PH. Evolving role of adiponectin in cancer-controversies and update. Cancer Biology \& Medicine 2016; 13: 101-119.

10. Buzzetti E, Pinzani M, Tsochatzis EA. The multiple-hit pathogenesis of non-alcoholic fatty liver disease (NAFLD). Metabolism 2016; 65: 1038-1048.

11. Armstrong MJ, Adams LA, Canbay A, Syn WK. Extrahepatic complications of nonalcoholic fatty liver disease. Hepatology 2014; 59: 1174-1197.

12. Lonardo A, Nascimbeni F, Mantovani A, et al. Hypertension, diabetes, atherosclerosis and NASH: Cause or consequence? J Hepatol 2018; 68: 335-352.

13. Byrne CD, Targher G. NAFLD: a multisystem disease. J Hepatol 2015; 62: 47-64.

14. Browna JC, Harhay MO, Harhayc MN. Nonalcoholic fatty liver disease and mortality among cancer survivors. Cancer Epidemiol 2017; 48: 104-109.

15. Saltiel AR, Kahn CR. Insulin signalling and the regulation of glucose and lipid metabolism. Nature 2001; 414: 799-806.

16. Ish-Shalom D, Christoffersen CT, Vorwerk P, et al. Mitogenic properties of insulin and insulin analogues mediated by the insulin receptor. Diabetologia 1997; 40: 25-31.

17. Park SE, Park CY, Sweeney G. Biomarkers of insulin sensitivity and insulin resistance: Past, present and future. Crit Rev Clin Lab Sci 2015; 52: 180-190.

18. Tam CS, Xie W, Johnson WD, et al. Defining insulin resistance from hyperinsulinemic-euglycemic clamps. Diabetes Care 2012; 35: 1605-1610.

19. Kahn SE, Hull RL, Utzschneider KM. Mechanisms linking obesity to insulin resistance and type 2 diabetes. Nature 2006; 444: 840-846.

20. Kahn SE, Prigeon RL, McCulloch DK, et al. Quantification of the relationship between insulin sensitivity and beta-cell function in human subjects. Evidence for a hyperbolic function. Diabetes 1993; 42: 1663-1672.

21. Chen C, Chmelova H, Cohrs CM, et al. Alterations in $\beta$-Cell Calcium Dynamics and Efficacy Outweigh Islet Mass Adaptation in Compensation of Insulin Resistance and Prediabetes Onset. Diabetes 2016; 65: 2676-2685.

22. Ashcroft FM, Rorsman P. Diabetes mellitus and the $\beta$ cell: the last ten years. Cell 2012; 148: 1160-1171.

23. Cerf ME. Beta Cell Dysfunction and Insulin Resistance. Front Endocrinol (Lausanne) 2013; 4: 37.

24. Hui JM, Sud A, Farrell GC, et al. Insulin resistance is associated with chronic hepatitis $C$ virus infection and fibrosis progression [corrected]. Gastroenterology 2003; 125: 1695-1704.

25. Bedinger DH, Goldfine ID, Corbin JA, et al. Differential Pathway Coupling of the Activated Insulin Receptor Drives Signaling Selectivity by XMetA, an Allosteric Partial Agonist Antibody. J Pharmacol Exp Ther 2015; 353: 35-43.

26. Belfiore A, Frasca F, Pandini G, et al. Insulin receptor isoforms and insulin receptor/insulin-like growth factor receptor hybrids in physiology and disease. Endocr Rev 2009; 30: 586-623.

27. Seino S, Bell GI. Alternative splicing of human insulin receptor messenger RNA. Biochem Biophys Res Commun 1989; 159: 312-316.

28. Frasca F, Pandini G, Scalia P, et al. Insulin receptor isoform A, a newly recognized, high affinity insulin-like growth factor II receptor in fetal and cancer cells. Mol Cell Biol 1999; 19: 278-288. 
29. Vogt B, Carrascosa JM, Ermel B, et al. The two isotypes of the human insulin receptor (HIR-A and HIR-B) follow different internalization kinetics. Biochem Biophys Res Commun 1991; 177: 1013-1018.

30. Sciacca L, Prisco M, Wu A, et al. Signaling differences from the $A$ and $B$ isoforms of the insulin receptor (IR) in 32D cells in the presence or absence of IR substrate-1. Endocrinology 2003; 144: $2650-2658$.

31. Medema SL, deVries-Smits AMM, van der Zon GCM, et al. Ras activation by insulin and epidermal growth factor through enhanced exchange of guanine nucleotides on p21Ras. Mol Cell Biol 1993; 13: 153-162.

32. Hansen BF, Danielsen GM, Drejer K, et al. Sustained signalling from the insulin receptor after stimulation with insulin analogues exhibiting increased mitogenic potency. Biochem J 1996; 315: 271-279.

33. McKay MM, Morrison DK. Integrating signals from RTKs to ERK/MAPK. Oncogene 2007; 26: 3113-3121.

34. Johnson GL, Lapadat R. Mitogen-activated protein kinase pathways mediated by ERK, JNK, and p38 protein kinases. Science 2002; 298: 1911-1912.

35. Dhillon AS, Hagan S, Rath O, et al. MAP kinase signalling pathways in cancer. Oncogene 2007; 26: 3279-3290.

36. Calle EE, Kaaks S. Overweight, obesity and cancer: epidemiological evidence and proposed mechanisms. Nat Rev Cancer 2004; 4: 79-91

37. Bedinger DH, Adams SH. Metabolic, anabolic, and mitogenic insulin responses: A tissue-specific perspective for insulin receptor activators. Mol Cell Endocrinol 2015; 415: 143-156.

38. Grimberg A, Cohen P. Role of Insulin-Like Growth Factors and Their Binding Proteins in Growth Control and Carcinogenesis. J Cell Physiol 2000; 183: 1-9.

39. Denley A, Carroll JM, Brierley GV, et al. Differential Activation of Insulin Receptor Substrates 1 and 2 by Insulin-Like Growth Factor-Activated Insulin Receptors. Mol Cell Biol 2007; 27: 3569-3577.

40. Belfiore A, Malaguarnera R. Insulin receptor and cancer. Endocr Relat Cancer 2011; 18: 125-147.

41. Rao Kondapally Seshasai S, Kaptoge S, Thompson A, et al. Emerging Risk Factors Collaboration. Diabetes mellitus, fasting glucose, and risk of cause-specific death. N Engl J Med 2011; 364: 829-841.

42. Williamson RM, Price JF, Glancy S, et al. Edinburgh Type 2 Diabetes Study Investigators. Prevalence of and risk factors for hepatic steatosis and nonalcoholic fatty liver disease in people with type 2 diabetes: the Edinburgh Type 2 Diabetes Study. Diabetes Care 2011; 34: 1139-1144.

43. Seko Y, Sumida Y, Tanaka S, et al. Insulin resistance increases the risk of incident type 2 diabetes mellitus in patients with non-alcoholic fatty liver disease. Hepatol Res 2018; 48: 42-51.

44. Singleton JR, Dixit VM, Feldman EL. Type I insulin-like growth factor receptor activation regulates apoptotic proteins. J Biol Chem 1996; 271: 31791-31794.

45. Lambert S, Vivario J, Boniver J, et al. Abnormal expression and structural modification of the insulin-like growth-factor-II gene in human colorectal tumors. Int J Cancer 1990; 46: 405-410.

46. Freier S, Weiss O, Eran M, et al. Expression of the insulin-like growth factors and their receptors in adenocarcinoma of the colon. Gut 1999; 44: 704-708.

47. Bergmann U, Funatomi H, Yokoyama M, et al. Insulin-like growth factor I overexpression in human pancreatic cancer: evidence for autocrine and paracrine roles. Cancer Res 1995; 55: 2007-2011.
48. Furukawa M, Raffeld M, Mateo C, et al. Increased expression of insulin-like growth factor I and/or its receptor in gastrinomas is associated with low curability, increased growth and development of metastases. Clin Cancer Res 2005; 11: 3233-3242.

49. Li C, Li J, Wu D, et al. The involvement of survivin in insulin-like growth factor 1-induced epithelial-mesenchymal transition in gastric cancer. Tumour Biol 2016; 37: 1091-1096.

50. Douglas JB, Silverman DT, Pollak MN, et al. Serum IGF-I, IGFII, IGFBP-3, and IGF-I/IGFBP-3 Molar Ratio and Risk of Pancreatic Cancer in the Prostate, Lung, Colorectal, and Ovarian Cancer Screening Trial. Cancer Epidemiol Biomarkers Prev 2010; 19: 2298-2306.

51. Li SR, Ng CF, Banerjea A, et al. Differential expression patterns of the insulin-like growth factor 2 gene in human colorectal cancer. Tumour Biol 2004; 25: 62-68.

52. Sopasakis VR, Sandqvist M, Gustafson B, et al. High local concentrations and effects on differentiation implicate interleukin-6 as a paracrine regulator. Obes Res 2004; 12: 454-460.

53. Gong Y, Dou LJ, Liang J. Link between obesity and cancer: role of triglyceride/ free fatty acid cycling. Eur Rev Med Pharmacol Sci 2014; 18: 2808-2820.

54. Rose DP, Vona-Davis L. The cellular and molecular mechanisms by which insulin influences breast cancer risk and progression. Endocr Relat Cancer 2012; 19: 225-241.

55. Warren RS, Yuan H, Matli MR, et al. Induction of vascular endothelial growth factor by insulin growth factor 1 in colorectal carcinoma. J Biol Chem 1996; 271: 29483-29488.

56. Goel HL, Mercurio AM. VEGF targets the tumour cell. Nat Rev Cancer 2013; 13: 871-882.

57. Niu G, Chen X. Vascular Endothelial Growth Factor as an Anti-angiogenic Target for Cancer Therapy. Curr Drug Targets 2010; 11: 1000-1017.

58. Wang X, Chen X, Fang J, et al. Overexpression of both VEGF-A and VEGF-C in gastric cancer correlates with prognosis, and silencing of both is effective to inhibit cancer growth. Int J Clin Exp Pathol 2013; 6: 586-597.

59. Ding MX, Lin XQ, Fu XY, et al. Expression of vascular endothelial growth factor- $\mathrm{C}$ and angiogenesis in esophageal squamous cell carcinoma. World J Gastroenterol 2006; 12: 4582-4585.

60. do Espírito Santo GF, Galera BB, Duarte EC, et al. Prognostic significance of vascular endothelial growth factor polymorphisms in colorectal cancer patients. World J Gastrointest Oncol 2017; 9: 78-86.

61. Ren L, Guo X, Shao X, et al. Endocrine gland-derived vascular endothelial growth factor modulates proliferation, apoptosis and migration in pancreatic cancer cells. Mol Med Rep 2015; 11: 4279-4284.

62. Rosmorduc O, Housset C. Hypoxia: a link between fibrogenesis, angiogenesis, and carcinogenesis in liver disease. Semin Liver Dis 2010; 30: 258-270.

63. Moon JO, Welch TP, Gonzalez FJ, et al. Reduced liver fibrosis in hypoxia-inducible factor-1alpha-deficient mice. Am J Physiol Gastrointest Liver Physiol 2009; 296: 582-592.

64. Lefere S, Van Steenkiste C, Verhelst X, et al. Hypoxia-regulated mechanisms in the pathogenesis of obesity and non-alcoholic fatty liver disease. Cell Mol Life Sci 2016; 73: 3419-3431.

65. Kukla M. Angiogenesis: a phenomenon which aggravates chronic liver disease progression. Hepatol Int 2013; 7: 4.

66. Majmundar AJ, Wong WJ, Simon MC. Hypoxia inducible factors and the response to hypoxic stress. Mol Cell 2010; 40: 294-309.

67. Suzuki T, Shinjo S, Arai T, et al. Hypoxia and Fatty Liver Disease. World J Gastroenterol 2014; 20: 15087-15097. 
68. Kaelin WG. The von Hippel-Lindau tumour suppressor protein: O2 sensing and cancer. Nat Rev Cancer 2008; 8: 865-873.

69. Paternostro C, David E, Novo E, et al. Hypoxia, angiogenesis and liver fibrogenesis in the progression of chronic liver diseases. World J Gastroenterol 2010; 16: 281-288.

70. Ciupińska-Kajor M, Hartleb M, Kajor M, et al. Hepatic angiogenesis and fibrosis are common features in morbidly obese patients. Hepatol Int 2013; 7: 233-240.

71. Kukla M, Gabriel A, Sabat D, et al. Association between liver steatosis and angiogenesis in chronic hepatitis C. Polish J Pathol 2010; 61: 154-160.

72. Tanaka F, Otake Y, Yanagihara K, et al. Evaluation of angiogenesis in non-small cell lung cancer. Comparison between anti-CD34 and anti-CD105 antibody. Clin Cancer Res 2001; 7: 410-415.

73. Rutkowski JM, Davis KE, Scherer PE: Mechanisms of obesity and related pathologies: the macro- and microcirculation of adipose tissue. FEBS J 2009; 276: 5738-5746.

74. Cusi K. The Role of Adipose Tissue and Lipotoxicity in the Pathogenesis of Type 2 Diabetes. Curr Diab Rep 2010; 10: 306-315.

75. Lefterova MI, Lazar MA. New developments in adipogenesis. Trends Endocrinol Metab 2009; 20: 107-114.

76. Hotamisligil GS, Erbay E. Nutrient sensing and inflammation in metabolic diseases. Nat Rev Immunol 2008; 8: 923-934.

77. Noonan DM, De Lerma Barbaro A, Vannini N, et al. Inflammation, inflammatory cells and angiogenesis: decisions and indecisions. Cancer Metastasis Rev 2008; 27: 31-40.

78. Sanna C, Rosso C, Marietti M, et al. Non-alcoholic fatty liver disease and extra-hepatic cancers. Int J Mol Sci 2016; 17: 717.

79. Bastard JP, Maachi M, van Nhieu JT, et al. Adipose tissue IL-6 content correlates with resistance to insulin activation of glucose uptake both in vivo and in vitro. J Clin Endocrinol Metab 2002; 87: 2084-2089.

80. De Visser KE, Eichten A, Coussens LM. Paradoxical roles of the immune system during cancer development. Nat Rev Cancer 2006; 6: 24-37.

81. Balkwill F, Charles KA, Mantovani A. Smoldering and polarized inflammation in the initiation and promotion of malignant disease. Cancer Cell 2005; 7: 211-217.

82. Hodgea DR, Hurtb EM, Farrara WL. The role of IL- 6 and STAT3 in inflammation and cancer. Eur J Cancer 2005; 41: 2502-2512.

83. Scheller J, Rose-John S. Interleukin-6 and its receptor: from bench to bedside. Med Microbiol Immunol 2006; 195: 173-183.

84. Conze D, Weiss L, Regen PS, et al. Autocrine production of interleukin 6 causes multidrug resistance in breast cancer cells. Cancer Res 2001; 61: 8851-8858.

85. Kai H, Kitadai Y, Kodama M, et al. Involvement of proinflammatory cytokines IL- $1 \beta$ and IL- 6 in progression of human gastric carcinoma. Anticancer Res 2005; 25: 709-713.

86. Sethi G, Shanmugam MK, Ramachandran L, et al. Multifaceted link between cancer and inflammation. Biosci Rep 2012; 32: 1-15.

87. Chung, YC, Chang YF. Serum interleukin-6 levels reflect the disease status of colorectal cancer. J Surg Oncol 2003; 83: 222-226.

88. Bao B, Ali S, Ahmad A, et al. Hypoxia-induced aggressiveness of pancreatic cancer cells is due to increased expression of VEGF, IL-6 and miR-21, which can be attenuated by CDF treatment. PLoS One 2012; 7: 50165.

89. Sethi G, Sung B, Aggarwal BB. TNF: A master switch for inflammation to cancer. Front Biosci 2008; 13: 5094-5107.

90. Aggarwal BB, Shishodia S, Sandur SK, et al. Inflammation and cancer: How hot is the link? Biochem Pharmacol 2006; 72 1605-1621.
91. Balkwill F. Tumour necrosis factor and cancer. Nat Rev Cancer 2009; 9: 361-371

92. Roubert A, Gregory K, Li Y, et al. The influence of tumor necrosis factor- $\alpha$ on the tumorigenic Wnt-signaling pathway in human mammary tissue from obese women. Oncotarget 2017; 8: 3612736136.

93. Michelotti GA, Xie G, Swiderska M, et al. Smoothened is a master regulator of adult liver repair. J Clin Invest 2013; 123: 23802394.

94. Verdelho Machado M, Diehl AM. Role of Hedgehog Signaling Pathway in NASH. Int J Mol Sci 2016; 17: 857.

95. Angulo P, Kleiner DE, Dam-Larsen S, et al. Liver fibrosis, but no other histologic features, is associated with long-term outcomes of patients with nonalcoholic fatty liver disease. Gastroenterology $2015 ; 149: 389-397$.

96. Guy CD, Suzuki A, Zdanowicz M, et al. Hedgehog pathway activation parallels histologic severity of injury and fibrosis in human nonalcoholic fatty liver disease. Hepatology 2012; 55 : 1711-1721.

97. Syn WK, Jung Y, Omenetti A, et al. Hedgehog-mediated epithelial-to-mesenchymal transition and fibrogenic repair in nonalcoholic fatty liver disease. Gastroenterology 2009; 137: 1478-1488.

98. Ye F, Jing YY, Guo SW, et al. Proliferative ductular reactions correlate with hepatic progenitor cell and predict recurrence in HCC patients after curative resection. Cell Biosci 2014; 4: 50.

99. $\mathrm{Hu} \mathrm{L}$, Lin $\mathrm{X}, \mathrm{Lu} \mathrm{H}$, et al. An overview of hedgehog signaling in fibrosis. Mol Pharmacol 2015; 87: 174-182.

100. Mehal WZ. The Gordian Knot of dysbiosis, obesity and NAFLD. Nat Rev Gastroenterol Hepatol 2013; 10: 637-644.

101. Michail S, Lin M, Frey MR, et al. Altered gut microbial energy and metabolism in children with non-alcoholic fatty liver disease. FEMS Microbiol Ecol 2015; 91: 1-9.

102. Zhu L, Baker SS, Gill C, et al. Characterization of gut microbiomes in nonalcoholic steatohepatitis (NASH) patients: a connection between endogenous alcohol and NASH. Hepatology 2013; 57: 601-609.

103. Boursier J, Mueller O, Barret M, et al. The severity of nonalcoholic fatty liver disease is associated with gut dysbiosis and shift in the metabolic function of the gut microbiota. Hepatology 2016; 63: 764-775.

104. Honda K, Littman DR. The microbiome in infectious disease and inflammation. Annu Rev Immunol 2012; 30: 759-795.

105. Peterson LW, Artis D. Intestinal epithelial cells: regulators of barrier function and immune homeostasis. Nat Rev Immunol 2014; 14: 141-153.

106. Llorente C, Schnabl B. The gut microbiota and liver disease. Cell Mol Gastroenterol Hepatol 2015; 1: 275-284.

107. Everard A, Belzer C, Geurts L, et al. Cross-talk between Akkermansia muciniphila and intestinal epithelium controls diet-induced obesity. Proc Natl Acad Sci USA 2013; 110: 9066-9071.

108. Sayin SI, Wahlstrom A, Felin J, et al. Gut microbiota regulates bile acid metabolism by reducing the levels of tauro-beta-muricholic acid, a naturally occurring FXR antagonist. Cell Metabolism 2013; 17: 225-235.

109. Kuribayashi H, Miyata M, Yamakawa H, et al. Enterobacteria-mediated deconjugation of taurocholic acid enhances ileal farnesoid X receptor signaling. Eur J Pharmacol 2012; 697: 132-138.

110. Claus SP, Tsang TM, Wang Y, et al. Systemic multicompartmental effects of the gut microbiome on mouse metabolic phenotypes. Mol Syst Biol 2008; 4: 219.

111. Yuan L, Bambha K. Bile acid receptors and nonalcoholic fatty liver disease. World J Hepatol 2015; 7: 2811-2818. 
112. Ridaura VK, Faith JJ, Rey Feet al. Gut microbiota from twins discordant for obesity modulate metabolism in mice. Science 2013; 341: 1241214.

113. Kapil S, Duseja A, Sharma BK, et al. Small intestinal bacterial overgrowth and toll-like receptor signaling in patients with non-alcoholic fatty liver disease. J Gastroenterol Hepatol 2016; 31: 213-221.

114. Miura K, Ohnishi H. Role of gut microbiota and Toll-like receptors in nonalcoholic fatty liver disease. World J Gastroenterol 2014; 20: 7381-7391.

115. Roh YS, Seki E. Toll-like receptors in alcoholic liver disease, non-alcoholic steatohepatitis and carcinogenesis. J Gastroenterol Hepatol 2013; 28: 38-42.

116. Spruss A, Kanuri G, Wagnerberger S, et al. Toll-like receptor 4 is involved in the development of fructose-induced hepatic steatosis in mice. Hepatology 2009; 50: 1094-1104.

117. Szabo G, Csak T. Inflammasomes in liver diseases. J Hepatol 2012; 57: 642-654.

118. Benetti E, Chiazza F, Patel NS, et al. The NLRP3 Inflammasome as a novel player of the intercellular crosstalk in metabolic disorders. Mediators Inflamm 2013; 2013: 678627.

119. Wree A, McGeough MD, Peña CA, et al. NLRP3 inflammasome activation is required for fibrosis development in NAFLD. Journal of Molecular Medicine 2014; 92: 1069-1082.

120. Matsuzaka T, Atsumi A, Matsumori R, et al. Elovl6 promotes nonalcoholic steatohepatitis. Hepatology 2012; 56: 2199-2208.

121. Miura K, Seki E, Ohnishi H, et al. Role of Toll-Like Receptors and Their Downstream Molecules in the Development of Nonalcoholic Fatty Liver Disease. Gastroenterol Res Pract 2010; 2010: 362847.

122. Brennan CA, Garrett WS. Gut microbiota, inflammation, and colorectal cancer. Annu Rev Microbiol 2016; 70: 395-411.

123. Baba Y, Iwatsuki M, Yoshida N, et al. Review of the gut microbiome and esophageal cancer: Pathogenesis and potential clinical implications. Ann Gastroenterol Surg 2017; 1: 99-104.

124. Signoretti M, Roggiolani R, Stornello C, et al. Gut microbiota and pancreatic diseases. Minerva Gastroenterol Dietol 2017; 63: 399-410.

125. Adolph TE, Grander C, Grabherr F, et al. Adipokines and Non-Alcoholic Fatty Liver Disease: Multiple Interactions. International Journal of Molecular Sciences 2017; 18: 1649.

126. Kukla M, Adamek B, Waluga M, et al. Hepatic Chemerin and Chemokine-Like Receptor 1 Expression in Patients with Chronic Hepatitis C. BioMed Research International 2014; 2014: 517820

127. Marra F, Bertolani C. Adipokines in liver diseases. Hepatology 2009; 50: 957-969.

128. Kukla M, Berdowska A, Gabriel A, et al. Association between hepatic angiogenesis and serum adipokine profile in non-obese chronic hepatitis C patients. Pol J Pathol 2011; 4: 218-228.

129. Kukla M, Ciupińska-Kajor M, Kajor M, et al. Liver visfatin expression in morbidly obese patients with nonalcoholic fatty liver disease undergoing bariatric surgery. Pol J Pathol 2010; 61: 147-153.

130. Hopkins BD, Goncalves MD, Cantley LC. Obesity and Cancer Mechanisms: Cancer Metabolism. J Clin Oncol 2016; 34: 4277-4283.

131. Ballinger A. Gastric leptin. Gut 1999; 44: 153-154.

132. Polyzos SA, Aronis KN, Kountouras J, et al. Circulating leptin in non-alcoholic fatty liver disease: a systematic review and meta-analysis. Diabetologia 2016; 59: 30-43.

133. Machado MV, Coutinho J, Carepa F, et al. How adiponectin, leptin, and ghrelin orchestrate together and correlate with the severity of nonalcoholic fatty liver disease. Eur J Gastroenterol Hepatol 2012; 24: 1166-1172.

134. Raya A, Cleary MP. The potential role of leptin in tumor invasion and metastasis. Progress in Growth Factor Research 2017; 38: 80-97.

135. Fazolini NP, Cruz AL, Werneck MB, et al. Leptin activation of mTOR pathway in intestinal epithelial cell triggers lipid droplet formation, cytokine production and increased cell proliferation. Cell Cycle 2015; 14: 2667-2676.

136. Thrift AP. Determination of risk for Barrett's esophagus and esophageal adenocarcinoma. Curr Opin Gastroenterol 2016; 32: 319-324.

137. Duan X, Tang P, Zhang H, et al. Expression of leptin and adiponectin in esophageal squamous cell carcinoma and their clinical significance. Zhonghua Zhong Liu Za Zhi 2014; 36: 839-843.

138. Lee KN, Choi HS, Yang SY, et al. The role of leptin in gastric cancer: clinicopathologic features and molecular mechanisms. Biochem Biophys Res Commun 2014; 446: 822-829.

139. Zhao X, Huang K, Zhu Z, et al. Correlation between expression of leptin and clinicopathological features and prognosis in patients with gastric cancer. J Gastroenterol Hepatol 2007; 22: 1317-1321.

140. Healy LA, Howard JM, Ryan AM, et al. Metabolic syndrome and leptin are associated with adverse pathological features in male colorectal cancer patients. Colorectal Dis 2012; 14: 157-165.

141. Wang D, Chen J, Chen $\mathrm{H}$, et al. Leptin regulates proliferation and apoptosis of colorectal carcinoma through PI3K/Akt/ mTOR signalling pathway. J Biosci 2012; 37: 91-101.

142. Uchiyama $\mathrm{T}$, Takahashi $\mathrm{H}$, Endo $\mathrm{H}$, et al. Role of the long form leptin receptor and of the STAT3 signaling pathway in colorectal cancer progression. Int J Oncol 2011; 39: 935-940.

143. Robinson K, Prins J, Venkatesh B. Clinical review: Adiponectin biology and its role in inflammation and critical illness. Critical Care 2011; 15: 221.

144. Katira A, Tan PH. Evolving role of adiponectin in cancer-controversies and update. Cancer Biology \& Medicine 2016; 13: 101-119.

145. Pérez-Hernández AI, Catalán V, Gómez-Ambrosi J, et al. Mechanisms linking excess adiposity and carcinogenesis promotion. Front Endocrinol (Lausanne) 2014; 5: 65.

146. Sugiyama M, Takahashi H, Hosono K, et al. Adiponectin inhibits colorectal cancer cell growth through the AMPK/mTOR pathway. Int J Oncol 2009; 34: 339-344.

147. Otani K, Ishihara S, Yamaguchi H, et al. Adiponectin and colorectal cancer. Surg Today 2017; 47: 151.

148. Lee CH, Woo YC, Wang Y, et al. Obesity, adipokines and cancer: an update. Clin Endocrinol 2015; 83: 147-156.

149. Dalamaga M, Diakopoulos KN, Mantzoros CS. The role of adiponectin in cancer: a review of current evidence. Endocrine Reviews 2012; 33: 547-594.

150. Polyzos SA, Toulis KA, Goulis DG, et al. Serum total adiponectin in nonalcoholic fatty liver disease: a systematic review and meta-analysis. Metabolism 2011; 60: 313-326.

151. Chu SH, Lee MK, Ahn KY, et al. Chemerin and adiponectin contribute reciprocally to metabolic syndrome. PLoS One 2012; 7: 34710.

152. Guenther M, James R, Marks J, et al. Adiposity distribution influences circulating adiponectin levels. Transl Res 2014; 164 : 270-277.

153. Yıldırım A, Bilici M, Cayır K, et al. Serum adiponectin levels in patients with esophageal cancer. Jpn J Clin Oncol 2009; 39: 92-96. 
154. Ishikawa M, Kitayama J, Kazama S, et al. Plasma adiponectin and gastric cancer. Clin Cancer Res 2005; 11: 466-472.

155. Chen MW, Ye S, Zhao LL, et al. Association of plasma total and high-molecular-weight adiponectin with risk of colorectal cancer: an observational study in Chinese male. Med Oncol 2012; 29: 3129-3135.

156. Nagaraju GP, Aliya S, Alese OB. Role of adiponectin in obesity related gastrointestinal carcinogenesis. Cytokine \& Growth Factor Reviews 2015; 26: 83-93.

157. Ntikoudi E, Kiagia M, Boura P, et al. Hormones of adipose tissue and their biologic role in lung cancer. Cancer Treat Rev 2014; 40: 22-30

158. Pagano C, Soardo G, Pilon C, et al. Increased serum resistin in nonalcoholic fatty liver disease is related to liver disease severity and not to insulin resistance. J Clin Endocrinol Metab 2006; 91: 1081-1086.

159. Senates E, Colak Y, Yesil A, et al. Circulating resistin is elevated in patients with non-alcoholic fatty liver disease and is associated with steatosis, portal inflammation, insulin resistance and nonalcoholic steatohepatitis scores. Minerva Med 2012; 103: 369-376.

160. Shen C, Zhao CY, Wang W, et al. The relationship between hepatic resistin overexpression and inflammation in patients with nonalcoholic steatohepatitis. BMC Gastroenterol 2014; 14: 39.

161. Ikeda Y, Tsuchiya H, Hama S, et al. Resistin affects lipid metabolism during adipocyte maturation of 3T3-L1 cells. FEBS J 2013; 280: 5884-5895.

162. Riondino S, Roselli M, Palmirotta R, et al. Obesity and colorectal cancer: Role of adipokines in tumor initiation and progression. World J Gastroenterol 2014; 20: 5177-5190.

163. Nieman KM, Romero IL, Van Houten B, et al. Adipose tissue and adipocytes support tumorigenesis and metastasis. Biochim Biophys Acta 2013; 1831: 1533-1541.

164. Gong W-J, Zheng W, Xiao L, et al. Circulating resistin levels and obesity-related cancer risk: A meta-analysis. Oncotarget 2016; 7: 57694-57704.

165. Diakowska D, Markocka-Mączka K, Szelachowski P, et al. Serum levels of resistin, adiponectin, and apelin in gastroesophageal cancer patients. Dis Markers 2014; 2014: 619649.

166. Hsieh Y-Y, Shen C-H, Huang W-S, et al. Resistin-induced stromal cell-derived factor-1 expression through Toll-like receptor 4 and activation of p38 MAPK/ NFKB signaling pathway in gastric cancer cells. J Biomed Sci 2014; 21: 59.

167. Fukuhara A, Matsuda M, Nishizawa M, et al. Visfatin: a protein secreted by visceral fat that mimics the effects of insulin. Science 2005; 307: 426-430.

168. Fazeli MS, Dashti H, Akbarzadeh S, et al. Circulating levels of novel adipocytokines in patients with colorectal cancer. Cytokine 2013; 62: 81-85.

169. Garten A, Petzold S, Körner A, et al. Nampt: linking NAD biology, metabolism and cancer. Trends Endocrinol Metab 2009; 20: $130-138$.

170. Gallí M, Van Gool F, Rongvaux A, et al. The nicotinamide phosphoribosyltransferase: a molecular link between metabolism, inflammation, and cancer. Cancer Res 2010; 70: 8-11.

171. Moschen AR, Kaser A, Enrich B, et al. Visfatin, an adipocytokine with proinflammatory and immunomodulating properties. J Immunol 2007; 178: 1748-1758.

172. Tilg H, Moschen AR. Role of adiponectin and PBEF/visfatin as regulators of inflammation: involvement in obesity-associated diseases. Clin Sci (Lond) 2008; 114: 275-288.

173. Auguet T, Terra X, Porras JA, et al. Plasma visfatin levels and gene expression in morbidly obese women with associated fatty liver disease. Clin Biochem 2013; 46: 202-208.
174. Nakajima TE, Yamada Y, Hamano T, et al. Adipocytokine levels in gastric cancer patients: resistin and visfatin as biomarkers of gastric cancer. J Gastroenterol 2009; 44: 685.

175. Bi TQ, Che XM, Liao XH, et al. Overexpression of Nampt in gastric cancer and chemopotentiating effects of the Nampt inhibitor FK866 in combination with fluorouracil. Oncol Rep 2011; 26: 1251-1257.

176. Lu GW, Wang QJ, Xia MM, et al. Elevated plasma visfatin levels correlate with poor prognosis of gastric cancer patients. Peptides 2014; 58: 60-64.

177. Nakajima TE, Yamada Y, Hamano T, et al. Adipocytokines as new promising markers of colorectal tumors: Adiponectin for colorectal adenoma, and resistin and visfatin for colorectal cancer. Cancer Science 2010; 101: 1286-1291.

178. Huang WS, Chen CN, Sze CI, et al. Visfatin induces stromal cell-derived factor- 1 expression by $\beta 1$ integrin signaling in colorectal cancer cells. J Cell Physiol 2013; 228: 1017-1024.

179. Kukla M, Zwirska-Korczala K, Hartleb M, et al. Serum chemerin and vaspin in non-alcoholic fatty liver disease. Scand J Gastroenterol 2010; 45: 235-242.

180. Bozaoglu K, Bolton K, McMillan J, et al. Chemerin is a novel adipokine associated with obesity and metabolic syndrome. Endocrinology 2007; 148: 4687-94.

181. Goralski KB, McCarthy TC, Hanniman EA, et al. A novel adipokine that regulates adipogenesis and adipocyte metabolism. J Biol Chem 2007; 282: 28175-28188.

182. Yoshimura T, Oppenheim JJ. Chemerin reveals a chimeric nature. JEM 2008; 205: 2187-2190.

183. Sell H, Divoux A, Poitou C, et al. Chemerin correlates with markers for fatty liver in morbidly obese patients and strongly decreases after weight loss induced by bariatric surgery. J Clin Endocrinol Metab 2010; 95: 2892-2896.

184. Takahashi M, Okimura Y, Iguchi G, et al. Chemerin regulates beta-cell function in mice. Sci Rep 2011; 1: 123.

185. Takahashi M, Takahashi Y, Takahashi K, et al. Chemerin enhances insulin signaling and potentiates insulin-stimulated glucose uptake in 3T3-L1 adipocytes. FEBS Lett 2008; 582: 573-578.

186. Krautbauer S, Wanninger J, Eisinger K, et al. Chemerin is highly expressed in hepatocytes and is induced in non-alcoholic steatohepatitis liver. Exp Mol Pathol 2013; 95: 199-205.

187. Erdogan S, Yilmaz FM, Yazici O, et al. Inflammation and chemerin in colorectal cancer. Tumor Biol 2016; 37: 6337.

188. Zhang J, Jin HC, Zhu AK, et al. Prognostic significance of plasma chemerin levels in patients with gastric cancer. Peptides 2014; 61: 7-11.

189. Wang C, Wu WK, Liu X, et al. Increased serum chemerin level promotes cellular invasiveness in gastric cancer: a clinical and experimental study. Peptides 2014; 51: 131-138.

190. Kumar JD, Kandola S, Tiszlavicz L, et al. The role of chemerin and ChemR23 in stimulating the invasion of squamous oesophageal cancer cells. Br J Cancer 2016; 114: 1152-1159.

191. Yeh YC, Sheu BS, Cheng HC, et al. Elevated serum matrix metalloproteinase- 3 and -7 in $\mathrm{H}$. pylori-related gastric cancer can be biomarkers correlating with a poor survival. Digestive Diseases and Sciences 2010; 55: 1649-1657.

192. Takahashi R, Tanaka S, Kitadai Y, et al. Expression of vascular endothelial growth factor and angiogenesis in gastrointestinal stromal tumor of the stomach. Oncology 2003; 64: 266-274.

193. Ashizawa T, Okada R, Suzuki Y, et al. Clinical significance of interleukin-6 (IL-6) in the spread of gastric cancer: role of IL-6 as a prognostic factor. Gastric Cancer 2005; 8: 124-131.

194. Fitzmaurice C, Allen C, Barber RM, et al. Global, regional and national cancer incidence, mortality, years of life lost, years 
lived with disability, and disability-adjusted life-years for 32 cancer Groups, 1990 to 2015: A systematic analysis for the global burden of disease study. JAMA Oncol 2017; 3: 524-548.

195. Holmes RS, Vaughan TL. Epidemiology and pathogenesis of esophageal cancer. Semin Radiat Oncol 2007; 17: 2-9.

196. Hung WC, Wu JS, Yang YC, et al. Nonalcoholic fatty liver disease vs. obesity on the risk of erosive oesophagitis. Eur J Clin Invest 2014; 44: 1143-1149.

197. He Q, Li J, Huang W, et al. Metabolic syndrome is associated with increased risk of Barrett esophagus. Medicine (Baltimore) 2016; 95: 4338

198. Velanovich V. Management of Barrett's Esophagus. Am Surg 2012; 78: 1193-1200.

199. Uzel M, Sahiner Z, Filik L. Non-alcoholic fatty liver disease, metabolic syndrome and gastric cancer: Single center experience. J BUON 2015; 20: 662.

200. Jemal A, Bray F, Center MM, et al. Global cancer statistics. CA Cancer J Clin 2011; 61: 69-90.

201. Torre LA, Bray F, Siegel RL, et al. Global cancer statistics, 2012. CA Cancer J Clin 2015; 65: 87-108.

202. Li D, Morris JS, Liu J, et al. Body mass index and risk, age of onset, and survival in patients with pancreatic cancer. JAMA 2009; 301: 2553-2562.

203. Esposito K, Chiodini P, Colao A, et al. Metabolic syndrome and risk of cancer. Diabetes Care 2012; 35: 2402-2411.

204. Aune D, Greenwood DC, Chan DS, et al. Body mass index, abdominal fatness and pancreatic cancer risk: A systematic review and non-linear dose-response meta-analysis of prospective studies. Ann Oncol 2012; 23: 843-852.

205. Ben Q, Xu M, Ning X, et al. Diabetes mellitus and risk of pancreatic cancer: A meta-analysis of cohort studies. Eur J Cancer 2011; 47: 1928-1937.

206. Johnson CM, Wei C, Ensor JE, et al. Meta-analyses of colorectal cancer risk factors. Cancer Causes Control 2013; 24: 1207-1222.

207. Hwang ST, Cho YK, Park JH, et al. Relationship of non-alcoholic fatty liver disease to colorectal adenomatous polyps. J Gastroenterol Hepatol 2010; 25: 562-567.

208. Lee YI, Lim YS, Park HS. Colorectal neoplasms in relation to non-alcoholic fatty liver disease in Korean women: A retrospective cohort study. J Gastroenterol Hepatol 2012; 27: 91-95.

209. Stadlmayr A, Aigner E, Steger B, et al. Nonalcoholic fatty liver disease: An independent risk factor for colorectal neoplasia. J Intern Med 2011; 270: 41-49.

210. Bhatt BD, Lukose $\mathrm{T}$, Siegel $\mathrm{AB}$, et al. Increased risk of colorectal polyps in patients with non-alcoholic fatty liver disease undergoing liver transplant evaluation. J Gastrointest Oncol 2015; 6: 459-468.

211. Wong VW-S, Wong GLH, Tsang SWC, et al. High prevalence of colorectal neoplasm in patients with non-alcoholic steatohepatitis. Gut 2011; 60: 829-836.

212. Lin XF, Shi KQ, You J, et al. Increased risk of colorectal malignant neoplasm in patients with nonalcoholic fatty liver disease: A large study. Mol Biol Rep 2014; 41: 2989-2997.

213. Touzin NT, Bush KNV, Williams CD, et al. Prevalence of colonic adenomas in patients with nonalcoholic fatty liver disease. Therap Adv Gastroenterol 2011; 4: 169-176.

214. Basyigit S, Uzman M, Kefeli A, et al. Absence of non-alcoholic fatty liver disease in the presence of insulin resistance is a strong predictor for colorectal carcinoma. Int J Clin Exp Med 2015; 8: 18601-18610.

215. Huang KW, Leu HB, Wang YJ, et al. Patients with nonalcoholic fatty liver disease have higher risk of colorectal adenoma after negative baseline colonoscopy. Colorectal Dis 2013; 15: 830-835. 